\title{
Impact of Inverted Interrupted Skin Suturing Versus Continous Suturing in Episioto- my on Postpartum Pain in Primigravida
}

\author{
Mahmoud Alalfy ${ }^{* 1}$ Amr Abbassy ${ }^{2}$ and Yossra Lasheen ${ }^{3}$
}

${ }^{1}$ Lecturer of Obstetrics and Gynecology, Assist, Reproductive Health and Family planning Department, National Research centre the senior fellow at Cairo fetal medicine unit, Egypt. Consultant at Aljazeerah Hospital, Egypt

${ }^{2}$ Lecturer, Researcher, of Obstetrics and Gynecology, Reproductive Health and Family planning Department, National Research centre, Egypt

${ }^{3}$ Lecturer of Obstetrics and Gynecology, Faculty of Medicine, Cairo University, Egypt

*Corresponding author: Mahmoud Alalfy, Lecturer, Researcher, Obstetrics and Gynecology, Reproductive Health and family planning department, National Research Centre, Egypt, The senior fellow at Cairo fetal medicine unit, Egypt. Consultant at Aljazeerah Hospital, Egypt, Tel: +2 1002611058, E-mail: mahmoudalalfy@ ymail.com

Citation: Mahmoud Alalfy, Amr Abbassy, Yossra Lasheen (2018) Impact of Inverted Interrupted Skin Suturing Versus Continous Suturing in Episiotomy on Postpartum Pain in Primigravida. J Gynecol Res 4(2): 205. doi: 10.15744/2454-3284.4.205

Received Date: June 02, 2018 Accepted Date: July 22, 2018 Published Date: September 07, 2018

\begin{abstract}
Introduction: Episiotomy is an incision that is made in perineum at the end of part of second stage of delivery.

Aim of the work: To detect the effect of continuous against interrupted technique of episiotomy closure on post-delivery pain.

Conclusion: The interrupted way of closing episiotomy shows less postoperative pain.
\end{abstract}

Keywords: Delivery; Postpartum; Pain

\section{Introduction}

Episiotomy is an incision that is made in perineum at the end of part of second stage of delivery. There are Long term sequels of episiotomy repair. A considerable number of ladies complains from perineal pain and up to twenty percent have long term complications e.g., dyspareunia [1]. The best method for repairing episiotomy is the method that isnot time consuming and lesser materials and causes lesser pain in the immediate and long term periods.

And so helps to start sexual relation early with a lesser pain and has a lower chance for resuturing [2]. The usual method that was applied for closing episiotomy was using three layer closure method [3]. Although there are various techniques to suture episiotomy, Now 2 well known methods of repair are used subcutaneous continuous and interrupted methods [4]. Most researchers believe that using continuous sutures to repair vagina and perineum has lesser pain than the way of closing it by interrupted sutures [5]. Vicryl Rapide $^{\mathrm{Tn}}$ is a multifilament material and is completely resorbed within fourty two days and doesnot retain a tensile strength 14 days postpartum [6].

\section{Patients and methods}

This was a randomized prospective study that was made in Aljazeerah hospital and Alsalam international hospital and Alsafwa Hospital, Egypt in the period from January 2017 till March 2018. 160 pregnant ladies were recruited to share in this study, and were consented before sharing in the study, The Allocation and Randomization; a computer generated randomization table was used for allocation in each study arm implementing a closed envelope system opened by operating room nurse during the time of randomization. The randomization allocation was 1:1. The two groups were randomly selected, 200 in each group. Eight cases dropped out follow up and did not come to the hospital to follow post-delivery, so they were excluded from the study and 152 
cases continue the study. All patients were delivered by normal vaginal delivery and a mediolateral episiotomy was made and then closure of the episiotomy was done using either a continous or inverted interrupted technique according to the group, Neither the patient nor the outcome assessor know the technique of closure. In the regular follow up of patients, they were asked about the pain after 48 hours and 10 days post-delivery.

\section{Results}

This was a randomized prospective study that was made in Aljazeerah hospital and Alsalam international hospital and Alsafwa Hospital, Egypt in the period from January 2017 till March 2018. 160 pregnant ladies were recruited to share in this study, and were consented before sharing in the study (Table 1, 2, 3 and 4), (Figure 1, 2, 3, 4, 5, 6 and 7).

\begin{tabular}{|c|c|c|c|}
\hline & & Count & $\%$ \\
\hline \multirow{2}{*}{ Technique Of Closure } & Inverted Interrupted & 76 & $50.0 \%$ \\
\cline { 2 - 4 } & Continous & 76 & $50.0 \%$ \\
\hline Gravidity \& Parity & Primigravida & 152 & $100.0 \%$ \\
\hline \multirow{2}{*}{ Postpartum Pain At 48 Hrs. } & Yes & 52 & $34.2 \%$ \\
\cline { 2 - 4 } & No & 100 & $65.8 \%$ \\
\hline \multirow{2}{*}{ Postoperative Pain At 10 Days } & Yes & 32 & $21.1 \%$ \\
\cline { 2 - 4 } & No & 120 & $78.9 \%$ \\
\hline
\end{tabular}

Table 1: Description of all patients included in the study

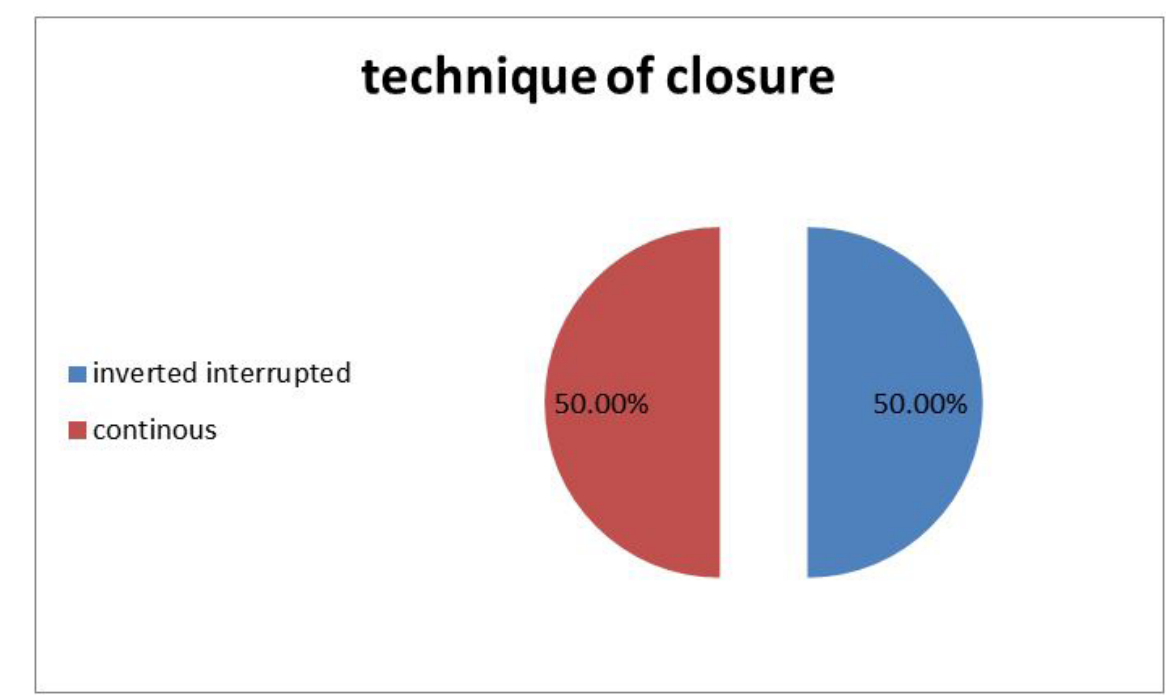

Figure 1: Shows the percent of cases with inverted technique and continous technique of episiotomy closure

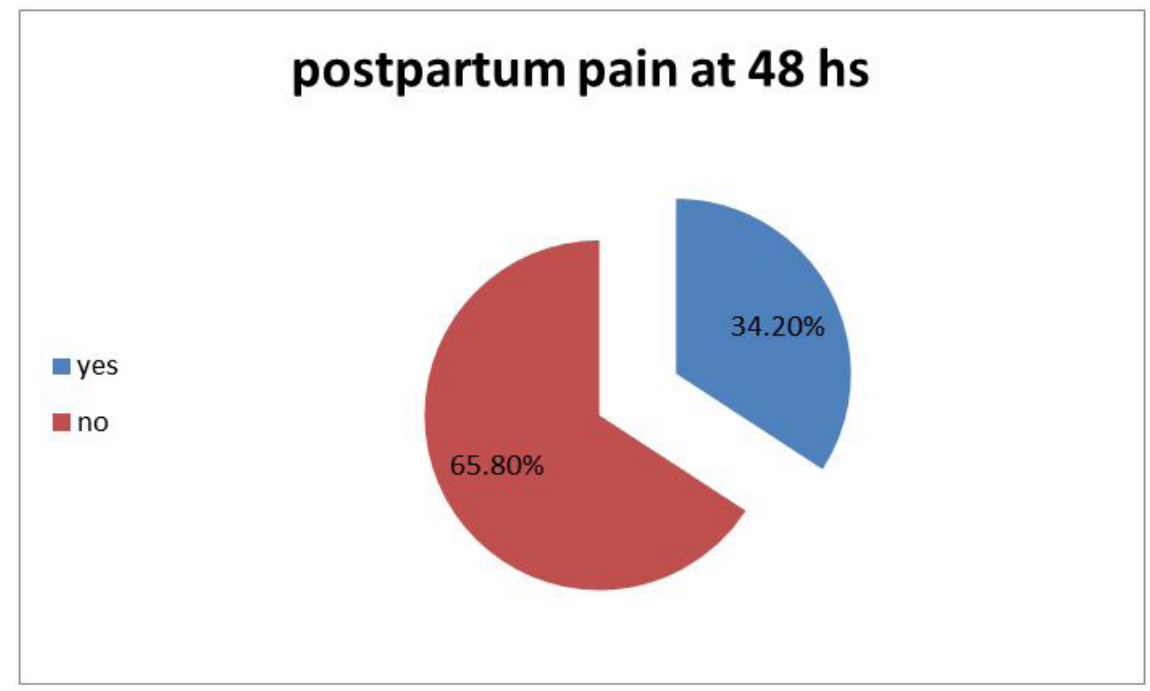

Figure 2: Shows the percent of cases who have postpartum pain among all cases 


\section{postoperative pain at 10 days}

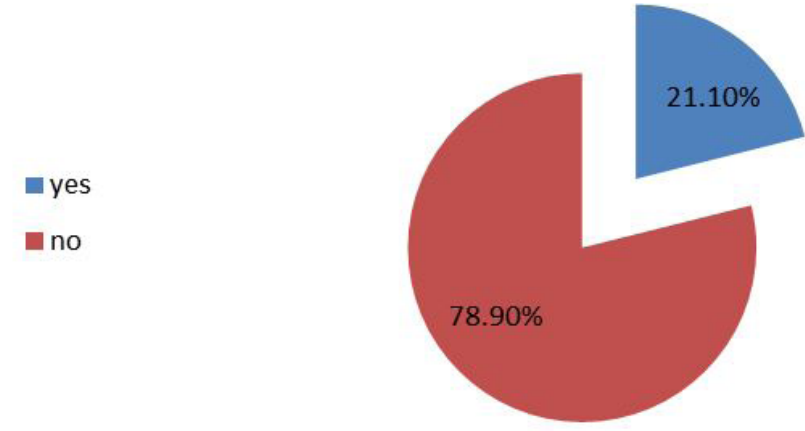

Figure 3: Shows the percent of cases who have postoperative pain after 10 days

\begin{tabular}{|c|c|c|}
\hline & Mean & Standard Deviation \\
\hline Age & 28.18 & 5.36 \\
\hline BMI & 21.78 & 1.82 \\
\hline Length Of Delivery (Hours) & 11.96 & 3.16 \\
\hline Blood Loss (Cc) & 597.37 & 147.81 \\
\hline Number Of Sutures & 7.55 & .80 \\
\hline
\end{tabular}

Table 2: Shows demographic data regarding age, BMI, length of delivery, blood loss and number of sutures

\begin{tabular}{|c|c|c|c|c|c|}
\hline & \multicolumn{4}{|c|}{ Technique Of Closure } & \\
\hline & \multicolumn{2}{|c|}{ Inverted interrupted } & \multicolumn{2}{|c|}{ Continous } & P value \\
\hline & Mean & Standard Deviation & Mean & Standard Deviation & \\
\hline Age & 27.34 & 4.88 & 29.03 & 5.71 & 0.053 \\
\hline BMI & 21.91 & 1.85 & 21.66 & 1.79 & 0.399 \\
\hline Length of delivery (hours) & 12.32 & 2.89 & 11.61 & 3.39 & 0.166 \\
\hline Blood loss (cc) & 550.00 & 140.00 & 644.74 & 140.85 & $<0.001$ \\
\hline Number of sutures & 7.39 & .88 & 7.71 & .69 & 0.015 \\
\hline
\end{tabular}

Table 3: Comparison between Inverted and continous groups

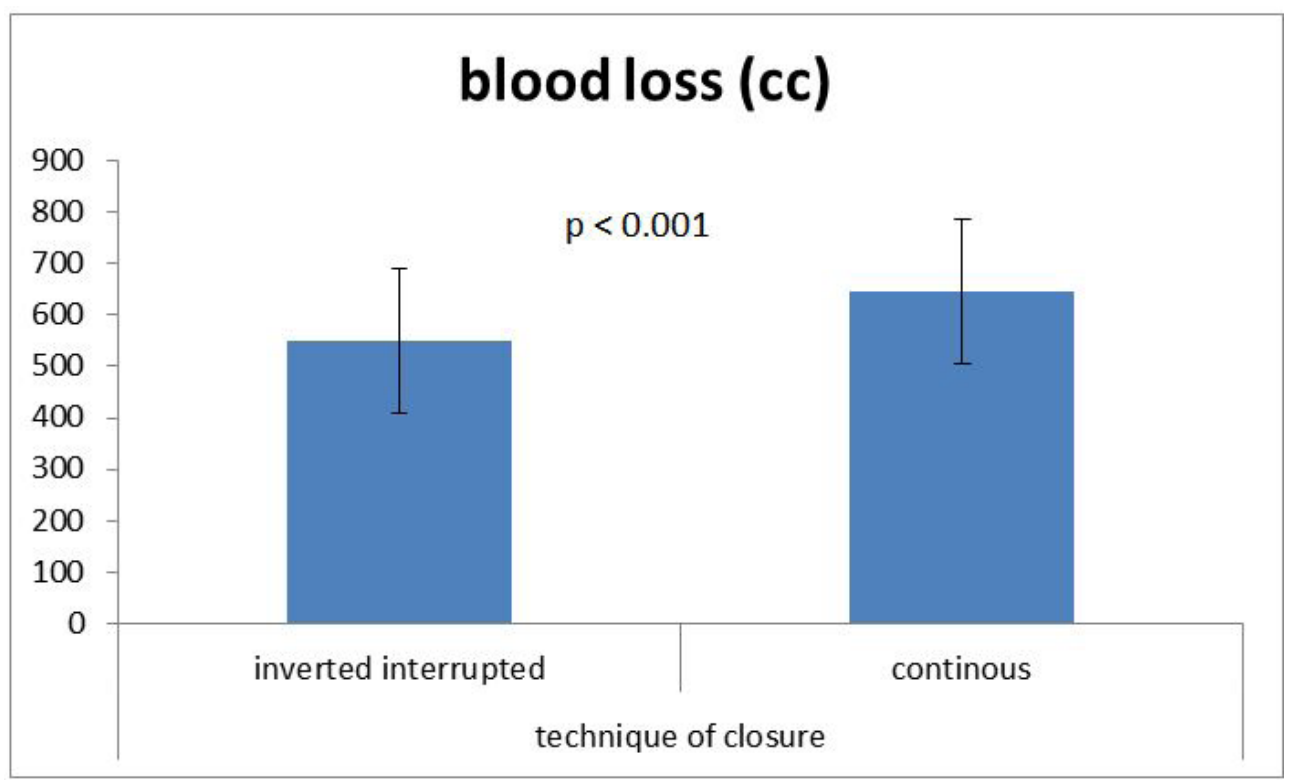

Figure 4: Figure showing mean \pm SD OF blood loss in the 2 groups 


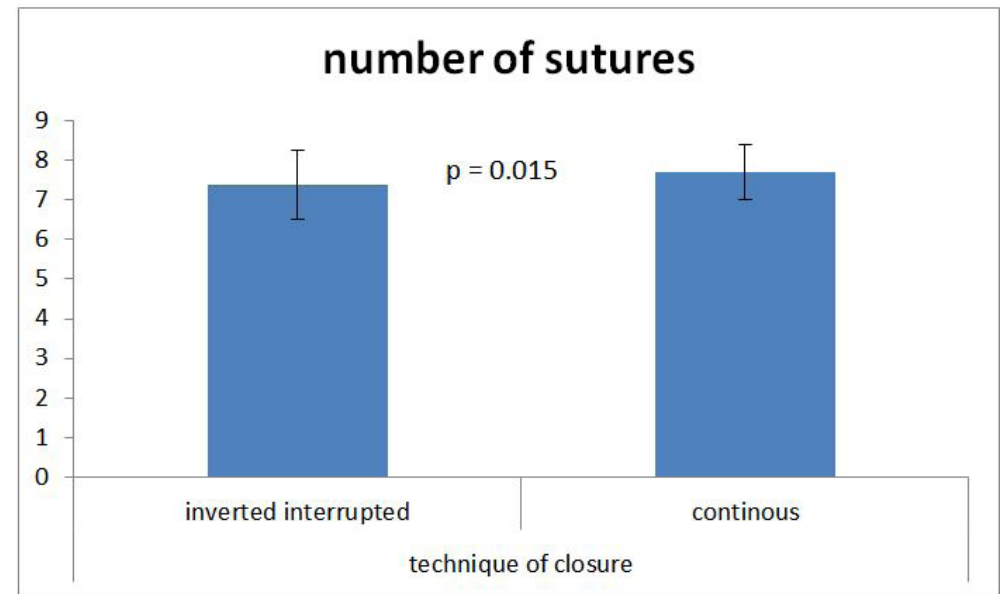

Figure 5: Showing mean $\pm \mathrm{SD}$ of number of sutures in the 2 groups

\begin{tabular}{|c|c|c|c|c|c|c|}
\hline & & \multicolumn{4}{|c|}{ Technique of Closure } & \multirow{3}{*}{$P$ value } \\
\hline & & \multicolumn{2}{|c|}{ Inverted Interrupted } & \multicolumn{2}{|c|}{ Continuous } & \\
\hline & & Count & $\%$ & Count & $\%$ & \\
\hline \multirow{2}{*}{ Postpartum Pain At $48 \mathrm{Hs}$} & Yes & 18 & $23.7 \%$ & 34 & $44.7 \%$ & 0.006 \\
\hline & No & 58 & $76.3 \%$ & 42 & $55.3 \%$ & \\
\hline \multirow{2}{*}{ Postoperative Pain At 10 Days } & Yes & 8 & $10.5 \%$ & 24 & $31.6 \%$ & 0.001 \\
\hline & No & 68 & $89.5 \%$ & 52 & $68.4 \%$ & \\
\hline
\end{tabular}

Table 4: Shows a comparison between interrupted versus continous group regarding postoperative pain at 48 hours and 10 days

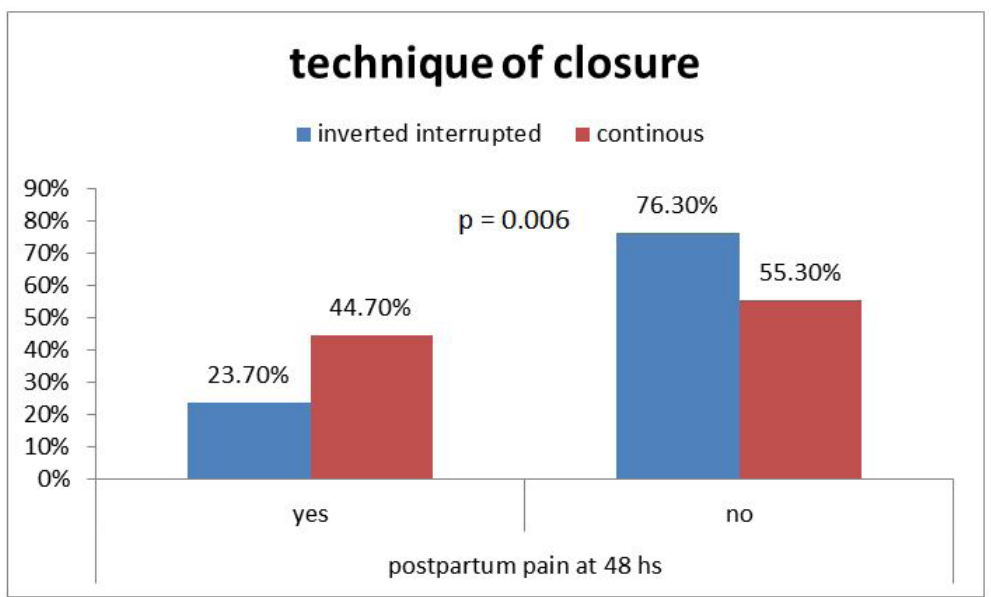

Figure 6: Showing postpartum pain at 48 hours in the 2 groups

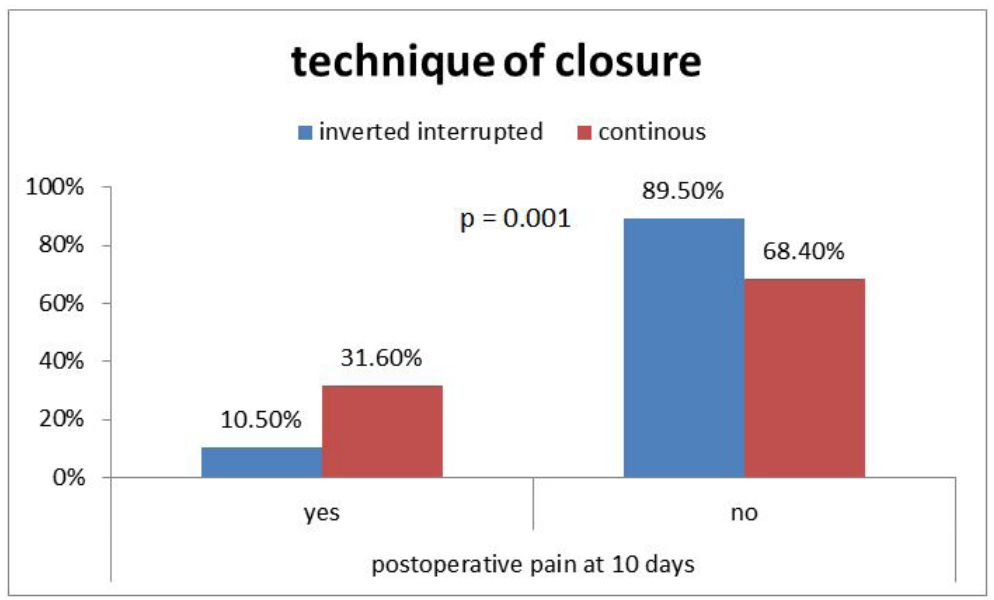

Figure 7: Showing postpartum pain at 10days in the 2 groups 


\section{Statistical Methods}

Data were coded and entered using the statistical package SPSS version 25. Data was summarized using mean and standard deviation for quantitative variables and frequencies (number of cases) and relative frequencies (percentages) for categorical variables. Comparisons between groups were done using unpaired t test (Chan, 2003a). For comparing categorical data, Chi square $\left(\mathrm{x}^{2}\right)$ test was performed. Exact test was used instead when the expected frequency is less than 5 (Chan, 2003b). P-values less than 0.05 were considered as statistically significant $[7,8]$.

\section{Discussion}

In the present study, the number of sutures was statistically significant with a $\mathrm{P}$ value less than 0.15 , indicating that in cases with a lesser number of sutures, they experienced less pain and this was more in inverted interrupted group In agreement with our research there was a study made by Rubina Iqbal et al. in 2012, he found more pain on day 0 in continuous group. Pain at day 10 in interrupted group was found to be higher as compared to continuous group. This benefit of continuous technique was consistently found in another study regarding pain associated with daily activities, suture material or skill of operator [9]. In contrast to our study, Southmead perineal suture study concluded no change in between the subcuticular and interrupted sutures results [10]. In the present study, there was a significant difference between the postpartum pains after 48 hours in the interrupted group when compared to the continous group with a P value 0.006. RCOG 2004 guideline also given level A gradation to the use of continuous subcuticular technique for perineal skin closure and a loose, continuous nonlocking suturing technique to oppose vaginal tissue and perineal muscle as it is associated with less short term pain compared with the interrupted method [11]. Also in the present study, In the present study, There was a significant difference between the postpartum pain after 10 days in the interrupted group when compared to the continuous group with a P value 0.006. In Pakistan, Perveen \& Shabbir, compared the methods of closure in interrupted and continuous closure ways of episiotomy on the 10th day and the 6th week postpartum. Similar to our results, they failed to find a significant discrepancy in the rate of healing of wound [12]. The results of a previous study made by Biswas Som and Biswas Srirupa in 2017. Showed that the rate of repair of episiotomy and the severity of pain were the same in both groups (interrupted and continuous) [13]. In a study by Perumal D et al., only 19.2\% of the study group experienced sever e pain, compared to $80.8 \%$ of the control group. Pain started to improve from third day onwards [14]. In a study done by Bose E et al. 7wound gaping (Dehisience) was recorded in five women sutured with CC, whereas, none of the women sutured with VR showed gaping of their episiotomy wound [15].

\section{Conclusion}

Our study revealed that there was a significant difference in the outcome of postoperative pain between primigravida who delivered with closure of episiotomy with inverted interrupted sutures with less number of patients who experienced postoperative pain than the ladies with episiotomy was closed by continuous technique especially when the interrupted technique was associated with less number of sutures.

\section{References}

1. Kalis V, Stepan J, Novotny Z (2008) Material and type of suturing of perineal muscles used in episiotomy repair in Europe. Pelviperineology 27: 17-22.

2. Valenzuela P, Saiz Puente MS, Valero JL, Azorín R, Ortega R, et al. (2009) Continuous versus interrupted sutures for repair of episiotomy or second-degree perineal tears: a randomised controlled trial. BJOG 116: 436-41.

3. Zafar S (2008) Comparison of single knot versus three layered techniques of perineal repair after vaginal delivery in women requiring episiotomy. J T UrkishGerman Gynaecol asso 9: 129-33.

4. Signorello LB, Harlow BL, Chekos AK, Repke JT (2001) Postpartum sexual functioning and its relationship to perineal trauma: a retrospective cohort study of primiparous women. Am J Obstet Gynecol 184: 81-8.

5. Kettle C, Hills RK, Ismail KM (2007) Continuous versus interrupted sutures for repair of episiotomy or second degree tears. Cochrane Database Syst Rev 17: CD000947.

6. Katz S, Izhar M, Mirelman D (1981) Bacterial adherence to surgical sutures. A possible factor in suture induced infection. Ann Surg 194: 35-41.

7. Chan YH (2003) Biostatistics102: Quantitative Data - Parametric \& Non-parametric Tests. Singapore Med J 44: 391-6.

8. Chan YH (2003) Biostatistics 103: Qualitative Data -Tests of Independence. Singapore Med J 44: 498-503.

9. Iqbal R, Intsar A, Khursheed S, Zafar S (2012) Outcome of Continuous Versus Interrupted Method of

Episiotomy Stitching. PJMHS 6: 759.

10. Mahomed K, Grant A, Ashurt H, James D (1989) The Southmead perineal suture study. A randomized comparision of suture materials and suturing techniques for repair of perineal trauma. Br J Obstet Gynaecol 96: 1272-80.

11. Royal College of Obstetricians and Gynaecologists (2015) Green-top Guideline No. 29: The management of third- and fourth-degree perineal tears, UK.

12. Perveen F, Shabbir T (2003) Perineal repair: comparsion of suture materials and suturing techniqus. Jurnal of Surgery Pakistan 14: $23-8$.

13. Som B, Srirupa B (2017) Interrupted versus subcutaneous continuous skin suture in Episiotomy Repair in Indian urban women: A Study. Int J Surg Surgical Tech 1: 000107.

14. Perumal D, Selvaraju D (2017) Comparative study of episiotomy repair: absorbable synthetic versus chromic catgut suture material. Int J Reprod Contracept Obstet Gyneco 1 6: 2186-90.

15. Bose E, Samant M, Lal P, Mishra S, Ghosh A (2013) Comparison of impact of polyglactin 910 (Vicryl rapide) and chromic catgut sutures on perineal pain following episiotomy wound repair in eastern Indian patients. J Sci Soc 40: 95-8. 


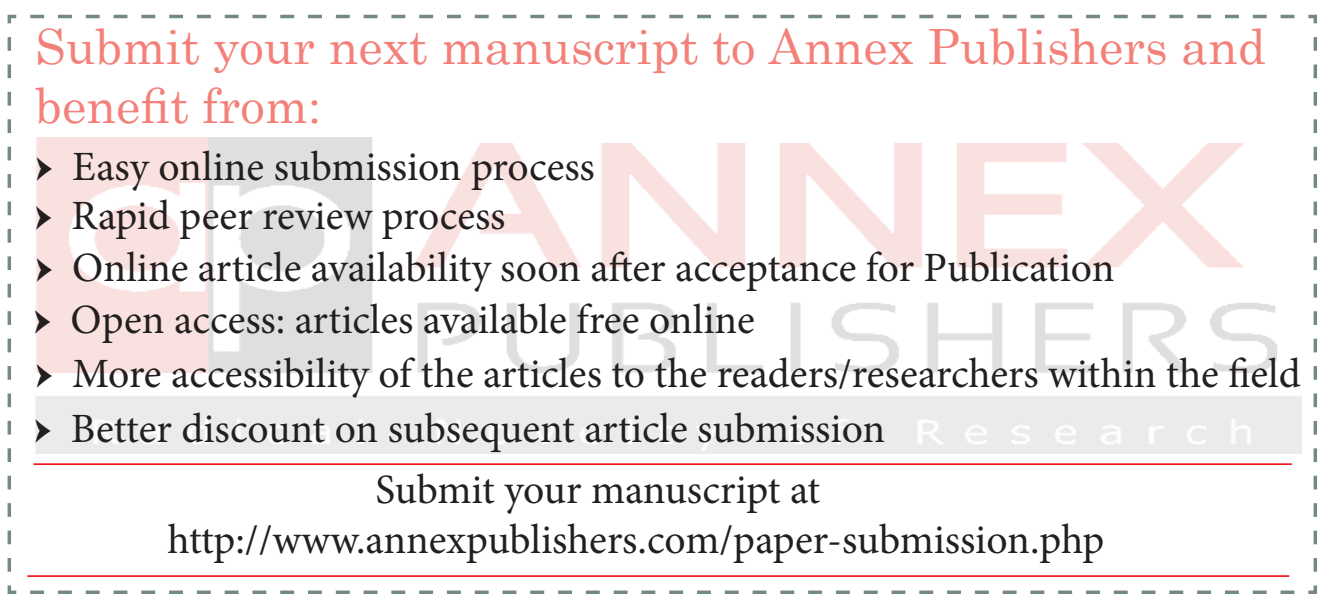

